\title{
Echocardiographic assessment of cardiac dysfunction in maintenance hemodialysis patients
}

\author{
Md Zahid Alam¹, Mohammad Zakir Hossain ${ }^{2}$
}

\begin{abstract}
Background and Objectives: The hemodialysis (HD) procedure may acutely induce regional left ventricular systolic dysfunction. This study evaluated the echocardiographic parameters in patients with End Stage Renal Disease (ESRD) on HD and to correlate those with clinical findings, more specifically to see whether there is any change in ejection fraction (EF) by developing new regional wall motion abnormality (RWMA) after hemodialysis, and to correlate these changes with the symptoms \& hemodynamic condition of the patients.

Methodology: This prospective observational study was carried on a total of 100 adult ambulant patients with end stage renal disease (ESRD) on maintenance hemodialysis in the department of Hemodialysis, BIRDEM General Hospital, Shahbag, Dhaka. Their echocardiogram was done $30 \mathrm{~min}$ before and after the hemodialysis.

Result: It was revealed that majority of the patients were above 60 years (39\%), and male to female ratio of about 3:2. The study subjects had diabetes mellitus (79\%), hypertension (96\%), dyslipidemia (42\%), and family history of ischemic heart disease (24\%). Chest pain and breathlessness were present in $31 \%$ and $42 \%$ subjects respectively before hemodialysis. Palpitation (23\%), dizziness (19\%), oedema (43\%) and raised JVP (15\%) were seen in the study subjects. Mean ( $\pm S D)$ serum creatinine level was 9.38 ( \pm 2.22$) \mathrm{mg} / \mathrm{dl}$ and hemoglobin level was 9.0 ( \pm 1.08$) \mathrm{g} / \mathrm{dl}$. Ejection fraction (EF) before hemodialysis were $\geq 55,40-54$ \& 30-39 in 62\%, 34\% and 4\% study subjects respectively and after hemodialysis it was $\geq 55,40-54 \& 30-39$ in 44\%, 46\% and 10\% study subjects respectively. After HD, left ventricular failure ( $L V F)$ occurred in $32 \%$ subjects. HD-induced regional left ventricular systolic dysfunction occurred in total 36 patients (36\%) and total 14 (14\%) patients developed LVF 30 minutes after dialysis. Patients with hemodialysis-induced left ventricular systolic dysfunction were more in those who had worse predialysis EF. Blood pressure, heart rate, chest pain, palpitation, raised Jugular Venous Pressure (JVP) and edema did not differ significantly before and after hemodialysis. Simple regression analysis revealed that the hemodialysis procedure significantly $(P<0.05)$ induce regional left ventricular systolic dysfunction.
\end{abstract}

Conclusions: HD acutely induces regional wall motion abnormalities in a significant proportion of patients. It occurs within 30 min after hemodialysis and is not related to changes in blood pressure, heart rate, JVP and oedema.

Key words: Hemodialysis (HD), Ejection fraction (EF), End Stage Renal disease (ESRD).

\section{Introduction:}

Chronic kidney disease (CKD) is a worldwide public health problem. ${ }^{1}$ CKD may culminate into renal failure which requires treatment with dialysis or transplantation - the most visible outcome of CKD. However, ischemic heart disease (IHD) is also frequently associated with CKD, which is important because individuals with CKD are more likely to die of IHD than to develop kidney failure. ${ }^{2,3}$ IHD in CKD is treatable and potentially preventable, and CKD appears to be

1. Dr. Md Zahid Alam, FCPS (Medicine), Associate Professor, Dept of Cardiology, BIRDEM General Hospital, Shahbag, Dhaka-1000

2. Dr. Mohammad Zakir Hossain. Senior Medical Officer, Dept of Hemodialysis, BIRDEM General Hospital, Shahbag, Dhaka-1000

\section{Corresponding Author:}

Dr. Md Zahid Alam

Associate Professor

Dept of Cardiology

BIRDEM General Hospital, Shahbag, Dhaka-1000

email: ilazybear@yahoo.com a risk factor for IHD. Dialysis patients with ischemic heart disease may not necessarily have large-vessel coronary disease. Patients may have ischemia secondary to the combined effects of volume overload and left ventricular hypertrophy $(\mathrm{LVH})$, which causes increased oxygen demand, and small vessel coronary disease, which causes decreased oxygen supply. Patients with CKD also have a high prevalence of arteriosclerosis and remodeling of large arteries. ${ }^{4}$ Remodeling may be due to either pressure overload, which is distinguished by wall hypertrophy and an increased wall-to-lumen ratio, or flow overload, which is characterized by a proportional increase in arterial diameter and wall thickness. ${ }^{3}$ Patients with CKD also have a high prevalence of cardiomyopathy. ${ }^{5}$ Hypertension and arteriosclerosis result in pressure overload and lead to concentric LVH (increased wall-to-lumen ratio), whereas anemia, fluid overload, and arteriovenous fistulas result in volume overload and primarily lead to left ventricular dilatation with LVH. These structural abnormalities may lead to diastolic and systolic dysfunction and may be detectable by echocardiography. Clinical presentations of cardiomyopathy include heart failure and ischemic heart disease, even in the absence of arterial vascular 
disease. ${ }^{3}$ Cardiac failure develops in as many as 25 to $50 \%$ of HD patients and confers a dramatic reduction in probability of survival. ${ }^{6}$ In addition, a significant percentage of cardiac mortality is due to sudden death, ${ }^{7}$ which seems to be temporarily related to the dialysis procedure. ${ }^{8}$ Myocardial ischemia may be precipitated by HD; a variety of studies have confirmed dialysis-induced myocardial ischemia. ${ }^{9}$ Short intermittent HD treatments exert significant hemodynamic effects, and 20 to $30 \%$ of treatments are complicated by intradialytic hypotension. ${ }^{6}$

Echocardiography is a non-invasive diagnostic technique which provides information regarding cardiac function and hemodynamics. In clinical practice, visual (eye ball) assessment via Two-Dimensional (2D) Echocardiography provides a rapid evaluation of regional systolic function. ${ }^{10}$ Determining the spectrum of echocardiographic abnormalities in these patients can change our vision in prevention of mortality in this group of chronically ill patients. In this study, we assessed the effects of hemodialysis on global and regional LV systolic function by serial echocardiography before and after dialysis using the routine systolic measurements for clinical practice that are recommended by the American Society of Echocardiography. ${ }^{11}$

\section{Materials and methods}

This prospective observational study was carried out to evaluate 100 adult subjects of known ESRD on maintenence hemodialysis in hemodialysis unit of BIRDEM General Hospital, Shahbag, Dhaka with the general objective to determine the echocardiographic parameters in patients with ESRD on haemodialysis and to correlate those with clinical findings. All ambulent adult patients (above 18 years of age) of both sex on maintainance HD (both twice or thrice weekly dialysis schedule) attending in hemodialysis unit. We excluded those patients who were irregular and less than three months on maintenance HD, not willing to be included in the study, and known psychiatric cases. The objective of the study was discussed in details with the patients or their attendants before their decision to enroll themselves into the study and written consent was taken. Clinical examination, relevant biochemical tests and Echocardiography were done and data collected in a pre-designed structured data collection sheets. Echocardiography was done before and after hemodialysis. Echocardiogram was done by a single cardiologist to avoid subjective variation of RWMA and EF. Demographic information was prospectively recorded and substantiated by means of inspection of medical record. Information included was the subject's age, gender, medical and clinical history, followed by conduction of the study. All the relevant collected data were compiled on a master chart first. Then organized by using scientific calculated and standard statistical formulas, percentage was calculated to find out the proportion of the findings. Data entry and analysis were done using SPSS for windows version 17.0. Output of data and graphical representation was done using Microsoft Office chart and Microsoft-Word. $p$-value was considered as significant when it was $<0.05$. The results were presented in tables, figures, diagrams etc.

\section{Results}

All subjects under experiment $(\mathrm{n}=100)$ were divided into age, sex, associated risk factors, and presenting clinical features.

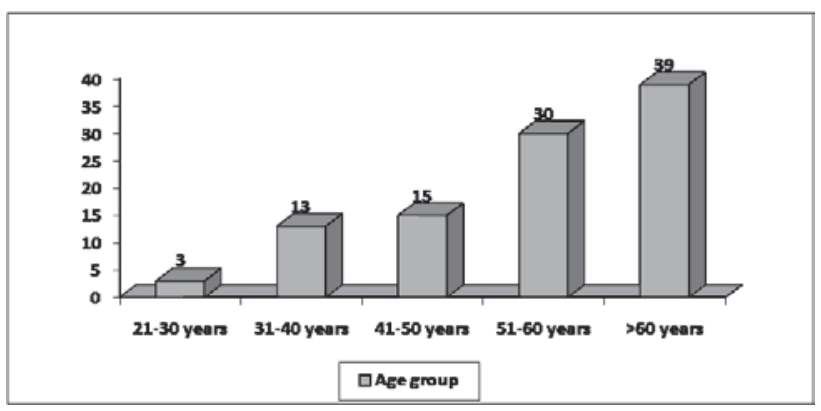

Figure 1: Age group distribution of the study subjects

It was shown in our study that majority of the patients were above 60 years of age (figure 1) and among the study subjects, $59 \%$ were male and the rest $41 \%$ were female.

The study subjects had hypertension (96\%), diabetes mellitus (79\%), dyslipidaemia (42\%), family history of IHD (24\%), tobacco intake $(21 \%)$, and alcohol intake $(2 \%)$ as pre-existing risk factors of IHD. $p$ - value was achieved by ANOVA test and was considered as significant when it was less than 0.05 . No significant difference was observed between male and female.

Presenting complaints were chest pain (31\%), breathlessness $(42 \%)$, cough $(44 \%)$, dizziness $(19 \%)$, and palpitation $(23 \%)$. Sixty five percent subjects were anaemic. Forty three percent subjects had generalized edema. Raised JVP was observed in fifteen percent subjects. Dehydration was present in six percent subjects. Cyanosis was absent in all subjects. $p$-value was achieved by ANOVA test and was considered as significant when it was less than 0.05. No significant difference was observed among the different age or sex groups. Mean $( \pm \mathrm{SD})$ baseline hemoglobin of the study population was $9.0( \pm 1.08) \mathrm{g} / \mathrm{dl}$, creatinine was $9.38( \pm 2.22)$ $\mathrm{mg} / \mathrm{dl}$, and blood urea was $102.18( \pm 70.07)$.

Table I: EF before and after hemodialysis

\begin{tabular}{lcc}
\hline $\begin{array}{l}\text { Ejection } \\
\text { fraction (\%) }\end{array}$ & $\begin{array}{c}\text { Before } \\
\text { hemodialysis } \\
\text { (Frequency/percent) }\end{array}$ & $\begin{array}{c}\text { After } \\
\text { hemodialysis } \\
\text { (Frequency/percent) }\end{array}$ \\
\hline 255 & $62 \%$ & $44 \%$ \\
$40-54$ & $34 \%$ & $46 \%$ \\
$30-39$ & $4 \%$ & $10 \%$ \\
\hline
\end{tabular}

Table II: Effect of hemodialysis on cardiovascular status

\begin{tabular}{lcc}
\hline Cardiovascular status & Frequency & Percent \\
\hline As before & 42 & 42.0 \\
Improved & 40 & 40.0 \\
Deteriorated & 18 & 18.0 \\
Total & 100 & 100.0 \\
\hline
\end{tabular}




\section{Discussion}

In this study, we found that LV regional systolic dysfunction developed after hemodialysis in about one-third of patients (36\%). Hemodialysis-induced regional LV systolic dysfunction and thus reduction of EF was mostly associated with pre-existent LV dysfunction, but it was not associated with age, sex or baseline renal status, ie, predialysis serum creatinine and blood urea level. The present study confirms earlier observations that hemodialysis may acutely induce regional LV dysfunction in a substantial proportion of patients. ${ }^{12-14}$ The reason of almost similar type of result can be explained by the nature of the study population: our study population had diabetes, background cardiovascular history, and some of them had pre-existing LV systolic dysfunction like previous study. However, some previous studies showed a lower incidence of HD-induced reduction of EF. ${ }^{15,16}$ It can be explained by the absence of diabetes and pre-existing cardiac disease in their study population. A second explanation might be the difference in the method used for the evaluation of regional LV systolic dysfunction. We used standard echocardiographic evaluation of regional LV function according to the guidelines of the American Society of Echocardiography, ${ }^{11}$ which is validated for routine clinical application.

Some previous studies, ${ }^{17,18}$ however, showed that almost all the post-dialysis patients developed significant LV systolic dysfunction (ie reduced EF). The main reason of this finding is that they used PET (Positron Emission Tomography) to detect HD-induced cardiac ischemia. PET - a nuclear machine which detects the metabolic process of the body, is no doubt, a better tool than conventional echocardiography to detect very minor ischemia. ${ }^{18}$

Univariate analysis suggested that traditional risk factors such as diabetes and previous history of CVD are related to a higher risk of cardiovascular events. On the other hand, age, smoking, and hypercholesterolemia were not risk factors for the occurrence of cardiovascular outcome. Although some studies showed a higher prevalence of traditional risk factors in the population with CKD than in the general population, ${ }^{19}$ high rates of cardiovascular complications have not been fully explained by such risk factors. ${ }^{20,21}$ Additionally, factors known to be non-traditional, such as anaemia, malnutrition, inflammatory state, alterations in calcium-phosphorus product, among others, have been implicated as independent factors associated with cardiovascular complications in dialysis patients. ${ }^{22-25}$ In our study, however, these factors did not correlate with the adverse cardiac outcome, because variables in our study are limited to only HD-induced change in $\mathrm{EF}$.

An important limitation of this study is the lack of angiographic evaluation of coronary arteries and therefore, the inability to correlate the echocardiographic findings with underlying coronary artery disease. This limitation should be considered in future studies on the effect of hemodialysis on LV function. A second limitation is the lack of a validated echocardiographic definition of HD-induced regional LV systolic dysfunction. In this study, hemodialysis-induced LV systolic dysfunction was defined as an increase in wall motion abnormality in two or more LV segments compared with predialysis. The use of other cutoff values would have influenced the prevalence of this entity as well as its association with outcome, because survival decreased with an increasing number of segments developing abnormal function during hemodialysis.

Another two limitations are, whether the reduction of EF was during or after HD was not certain. Because one study showed that reduction of EF was different during different time of HD and mostly occurred during early phase of HD. ${ }^{15}$ However, some studies showed that repeated HD may improve LV dysfunction over time. ${ }^{26,27}$ As our study was only two-session study, our study did not support this finding.

However, our study has several strengths. First, compared to recent trials, this study is much larger study that evaluated the acute effect of hemodialysis on LV global and regional systolic function. Second, we used routine and clinically applicable echocardiographic methods to evaluate global and regional LV systolic function. Third, the echocardiographic analysis of regional LV systolic function was performed by a single technician who was blinded to the order of echocardiography studies.

\section{References :}

1. National Institutes of Health, National Institute of Diabetes and Digestive and Kidney Diseases. US Renal Data System, USRDS 1998 Annual Data Report. Bethesda M: 1998. Available at: http://www.usrds.org/adr_1998.htm. Accessed September 12, 2003.

2. Shulman NB, Ford CE, Hall WD. Prognostic value of serum creatinine and effect of treatment of hypertension on renal function: results from the hypertension detection and follow-up program. The Hypertension Detection and Follow-up Program Cooperative Group. Hypertension 1989;13(S5):I80-93.

3. Sarnak MJ, Levey AS, Schoolwerth AC, Coresh j, Culleton B, Hamm LL, et al. Kidney Disease as a Risk Factor for Development of Cardiovascular Disease. A Statement From the American Heart Association Councils on Kidney in Cardiovascular Disease, High Blood Pressure Research, Clinical Cardiology, and Epidemiology and Prevention. Circulation 2003;108:2154-69.

4. London GM, Marchais SJ, Guerin AP, Metivier F, Adda H. Arterial structure and function in end-stage renal disease. Nephrol Dial Transplant 2002;17:1713-24.

5. Foley RN, Parfrey PS, Harnett JD, Kent GM, Martin CJ, Murray DC, et al. Clinical and echocardiographic disease in patients starting end stage renal disease therapy. Kidney Int 1995;47:186-92.

6. Harnett JD, Foley RN, Kent GM, Barre PE, Murray D, Parfrey PS. Congestive heart failure in dialysis patients: Prevalence, incidence, prognosis and risk factors. Kidney Int 1995;47: 884-90.

7. Bleyer AJ, Russell GB, Satko SG. Sudden and cardiac death rates in hemodialysis patients. Kidney Int 1999;55:1553-9.

8. Bleyer AJ, Hartman J, Brannon PC, Reeves-Daniel A, Satko SG, Russell G. Characteristics of sudden death in hemodialysis patients. Kidney Int 2006;69:2268-73.

9. Selby NM, McIntyre CW. The acute cardiac effects of dialysis. Semin Dial 2007;20:220-8. 
10. Esmaeilzadeh M, Parsaee M, Maleki M. The role of echocardiography in coronary artery disease and acute myocardial infarction. J Tehran Heart Cent 2013; 8(1): 1-13.

11. Lang RM, Bierig M, Devereux RB, Flachskampf FA, Foster E, Pellikka PA, et al. Chamber Quantification Writing Group; American Society of Echocardiography's Guidelines and Standards Committee; European Association of Echocardiography: Recommendations for chamber quantification: A report from the American Society of Echocardiography's Guidelines and Standards Committee and the Chamber Quantification Writing Group, developed in conjunction with the European Association of Echocardiography, a branch of the European Society of Cardiology. J Am Soc Echocardiogr 2005;18: 1440-63.

12. Dasselaar JJ, Slart RH, Knip M, Pruim J, Tio RA, McIntyre CW, et al. Haemodialysis is associated with apronounced fall in myocardial perfusion. Nephrol Dial Transplant 2009; 24: 604-10.

13. McIntyre CW, Burton JO, Selby NM, Leccisotti L, Korsheed S, Baker CS, et al. Hemodialysis-induced cardiac dysfunctionis associated with an acute reduction in global and segmental myocardial blood flow. Clin J Am Soc Nephrol 2008; 3: 19-26.

14. Burton JO, Jefferies HJ, Selby NM, McIntyre CW. Hemodialysisinduced repetitive myocardial injury results in global and segmental reduction in systolic cardiac function. Clin J Am SocNephrol 2009; 4: 1925-31.

15. Assa S, Hummel YM, Voors AA, Kuipers J, Westerhuis R, de Jong $\mathrm{PE}$, et al. Hemodialysis-Induced Regional Left Ventricular SystolicDysfunction: Prevalence, Patient and DialysisTreatment-Related Factors, and Prognostic Significance. Clin J Am Soc Nephrol 2012; 7: 1615-23.

16. Burton JO, Jefferies HJ, Selby NM, McIntyre CW. Hemodialysisinduced cardiac injury: Determinants and associatedoutcomes.Clin J Am Soc Nephrol 2009; 4: 914-20

17. McIntyre CW, Burton JO, Selby NM, Leccisotti L, Korsheed S, Baker CSR, et al. Hemodialysis-Induced Cardiac Dysfunction Is Associated with an Acute Reduction in Global and SegmentalMyocardial Blood Flow. Clin J Am Soc Nephrol 2008;3:19-26.
18. Siqueira TMA, Ferreira PAM, Monteiro FC, Filho NS, Ferreira ASP, Neto ES, et al. Echocardiographic Parameters as Cardiovascular Event Predictors in Hemodialysis Patients. Arq Bras Cardiol 2012; 99(2): 714-23

19. Longenecker JC, Coresh J, Powe NR, Levey AS, Fink NE, Martin $\mathrm{A}$, et al.Traditional cardiovascular disease risk factors in dialysispatients comparedwith the general population: the CHOICE Study. J Am Soc Nephrol 2002; 13(7): 1918-27.

20. Foley RN, Parfrey PS, Sarnak MJ. Clinical epidemiology of cardiovasculardisease in chronic renal disease. Am J Kidney Dis 1998; 32: S112-9.

21. Zoccali C, Mallamaci F, Tripepi G. Novel cardiovascular risk factors in endstage renal disease.J Am Soc Nephrol 2004; 15: S77-80.

22. Weiner DE, Tighiouart H, Vlagopoulos PT, Griffith JL, Salem DN, Levey AS, et al. Effects of anemia and left ventricular hypertrophy on cardiovascular disease in patients with chronic kidney disease. $\mathrm{J}$ Am Soc Nephrol 2005;16(6): 1803-10.

23. Kakiya R, Shoji T, Tsujimoto Y, Tatsumi N, Hatsuda S, Shinohara $\mathrm{K}$, et al. Bodyfat mass and lean mass as predictors of survival inhemodialysis patients.Kidney Int 2006; 70(3): 549-56.

24. Kalantar-Zadeh K, Kopple JD, Block G, Humphreys MH. A malnutritioninflammation score is correlated with morbidity and mortality inmaintenance hemodialysis patients. Am J Kidney Dis 2001; 38(6): 1251-63.

25. Block GA, Klassen PS, Lazarus JM, Ofsthun N, Lowrie EG, Chertow GM. Mineral metabolism, mortality, and morbidity in maintenance hemodialysis. J Am Soc Nephrol 2004; 15(8): 2208-18.

26. Yazdani I, Ahmed S, Yaqoob Z. Evaluation of the Effect of Haemodlalysis on Cardiac Dysfunction in Patients of Chronic Renal Failure. JPMA 1998; 48: 230-2.

27. Jefferies HJ, Virk B, Schiller B, Moran J, McIntyre CW. Frequent Hemodialysis Schedules Are Associated with Reduced Levels of Dialysis-induced Cardiac Injury (Myocardial Stunning). Clin J Am Soc Nephrol 2011; 6: 1326-32. 